\title{
Spatially referenced trap arrays detect sediment disposal impacts on lobsters and crabs in a New England estuary
}

\author{
Kerrie P. O'Donnell ${ }^{1,4, *}$, Richard A. Wahle ${ }^{2}$, Michael Bell ${ }^{3}$, Michael Dunnington ${ }^{2}$ \\ ${ }^{1}$ Island Institute, PO Box 648, 386 Main St., Rockland, Maine 04841, USA \\ ${ }^{2}$ Bigelow Laboratory for Ocean Sciences, 180 McKown Point Road, West Boothbay Harbor, Maine 04575, USA \\ ${ }^{3}$ The Centre for Environment, Fisheries and Aquaculture Science, Pakefield Road, Lowestoft, Suffolk NR33 0HT, UK
}

${ }^{4}$ Present address: University of British Columbia-Fisheries Centre, 2202 Main Mall, Vancouver, British Columbia V6T 1Z4, Canada

\begin{abstract}
We employed spatially referenced trap arrays and side-scan sonar mapping of the sea floor to assess the impact of late autumn sediment disposal on local American lobster Homarus americanus and rock crab Cancer irroratus abundance in the neighborhood of a disposal site for harbor dredge spoils in Penobscot Bay, Maine, USA. The assumption that impacts on lobsters would be minimized if disposal were conducted in late autumn, when the commercial lobster fishery is at a seasonal low and lobsters are believed to be moving to deeper water, was tested. Previous mark-recapture experiments conducted nearby established that trap catch rates strongly track trends in abundance. To our knowledge this is the first study in which geo-referenced trap-based sampling and seabed mapping have been used to assess the impact of an environmental perturbation on mobile benthic megafauna. We set 3 arrays of 24 traps: 1 array over the disposal area and 2 on adjacent unimpacted areas, all about $0.6 \mathrm{~km}^{2}$ in size. Two weeks prior to the onset of disposal and for 4 wk thereafter, we counted lobsters and rock crabs caught in the traps weekly and released them at the same trap location. Post-disposal side-scan sonar surveys revealed a mound of soft sediment not evident in pre-disposal surveys covering an estimated 44170 to $108881 \mathrm{~m}^{2}$ of seabed. No statistically significant impact of the sediment disposal was detected on lobster abundance. In contrast, within a few weeks of the onset of disposal, the overall catch of rock crabs increased dramatically in the disposal area and specifically on the patch of newly deposited sediment. These results indicate that spatially referenced trap arrays used in conjunction with seabed mapping provide a useful tool for evaluating change in the distribution and abundance of benthic megafauna at spatial scales as small as 10 s of meters. The findings also indicate that even for ecologically similar taxa, e.g. lobsters and crabs, the impact of such disposal events can be strongly species specific. While direct impacts to lobsters may be minimized after the autumn offshore migration, crabs, still abundant in the area, may be attracted to the food-rich sediments at the disposal site.
\end{abstract}

KEY WORDS: Anthropogenic disturbance $\cdot$ Dredge material disposal $\cdot$ Traps $\cdot$ Homarus americanus Cancer irroratus $\cdot$ Abundance

Resale or republication not permitted without written consent of the publisher

\section{INTRODUCTION}

Human alteration of marine habitats can pose hazards to resident biota and fisheries (Kester et al. 1983, Harvey et al. 1998, Watling \& Norse 1998, Grigalunas et al. 2001, Jackson et al. 2001). The magnitude and importance of these effects on ecosystems and human populations has increasingly been recognized by ecologists (Lubchenco et al. 1991, Vitousek et al. 1997). Methodologies that provide high spatial and temporal resolution of the impacts provide resource managers greater insights into both the nature of the impacts as 
well as strategies to mitigate them (Peterson \& Estes 2001). We describe a methodology that integrates seabed mapping and trap-based sampling to evaluate the impacts of sediment disposal on large mobile lobsters Homarus americanus and crabs Cancer irroratus in coastal New England, USA.

The disposal of dredged sediments from harbors and channels is widely practiced to maintain waterways and has been identified as an important environmental issue in coastal zone management (Van Dolah 1984). Disposed sediments and their turbidity plumes can bury organisms, fill in shelter space, clog gills and filter-feeding organs, and introduce hypoxia or toxic substances. Most benthic monitoring efforts on this topic have focused on changes in sediment composition, toxicity, and infaunal abundance and diversity (e.g. Jones 1986, Harvey et al. 1998). Very few studies, however, have addressed the impacts of disposal on mobile epibenthic megafauna (e.g. Wilber \& Clarke 1998). Several species of lobsters and crabs are conspicuous ecologically important consumers, in some cases comprising significant fisheries, yet the impact of habitat perturbations remains poorly understood for these organisms.

Impact assessment studies can be divided into 2 categories: those that simulate impacts explicitly for the purposes of an experiment, and those that take advantage of existing impacts and incorporate spatial and temporal controls into the assessment design as much as possible (Underwood 1991). In these cases rarely is it desirable or ethical to replicate the environmental impact (Underwood 1994). This study falls into the latter category. Scheduled disposal events sanctioned by the US Army Corps of Engineers and the State of Maine at a designated disposal site in Penobscot Bay created an opportunity to evaluate ecological impacts at a single location relative to adjacent unaffected areas.

In the present study, we applied a recently developed methodology involving spatially referenced trap arrays to assess relative changes in the spatial pattern of lobster and crab abundance by way of geo-referenced traps and habitat mapping (Dunnington et al. 2005). We evaluate changes in the immediate area of the disposal site before and after the onset of disposal activity. While trap catch rates are widely used to characterize population trends in marine decapods (e.g. Bell 2003, Frusher \& Hoenig 2003, Ziegler et al. 2004), to our knowledge this is the first application of trapping methodology in the context of an environmental impact study for marine megafauna. Terrestrial ecologists, in contrast, have widely utilized traps to quantify anthropogenic impacts on animal communities (e.g. effects of habitat fragmentation on small mammals, Bennett 1990; changes in arthropod diver- sity in response to land use, Rivers-Moore \& Samways 1996). However, because of the potential for traps to introduce biases due to changes in selectivity, catchability, and range of attraction, it is necessary to ground truth population trends by independent means. In our case, previous mark-recapture studies and diver ground-truthing with lobsters have demonstrated a strong correlation between catch rate and abundance at multiple study sites in Penobscot Bay (Dunnington et al. 2005). Lobster mark-recapture modeling associated with the present study and reported elsewhere further validates the use of trap catch rates as an index of abundance (Wahle et al. 2004).

The aim of the present study was to describe the approach enabling us to reveal, with relatively high spatial and temporal resolution, the contrasting response of lobsters and crabs to disposal events. To our knowledge this is the first time spatially referenced, trap-based sampling has been integrated with seabed mapping to evaluate the impacts of an environmental perturbation on mobile benthic megafauna.

\section{MATERIALS AND METHODS}

Study area. Penobscot Bay is home to several small commercial harbors, all of which support deepdraft shipping traffic. Periodically these harbors are dredged to maintain shipping channels. Sediments from these and other harbors are disposed of at the Rockland disposal site, centrally located in the bay, at approximately $75 \mathrm{~m}$ depth below mean low water. Penobscot Bay also happens to be one of the most productive lobster fishing grounds in New England (Steneck \& Wilson 2001). The disposal site is located in an area of the bay that is actively fished during the warmer months - May through November. While prior surveys of the disposal site have been conducted by the US Army Corps of Engineers (SAIC 1989, 2001), these studies primarily characterize bathymetry, substrata, and infaunal biota. Observations of lobsters were limited to video footage of a single specimen and a number of possible lobster burrows. Thus, for all practical purposes, the impact of dredged material disposal on large mobile decapods such as lobsters and crabs has not been assessed. In response to concern expressed by both harvesters and the Maine Department of Marine Resources, the US Army Corps of Engineers agreed to restrict disposal activities to the cooler months and to conduct an impact study on the effects of sediment disposal on lobster abundance and movements in the immediate area of the disposal site. While potential impacts on the lobster Homarus americanus fishery were the primary motivation of this study, once we began sampling, it became apparent that the rock 
crab Cancer irroratus comprised a prominent fraction of the catch, and because it is also commercially exploited to a limited extent, evaluating disposal impacts on these crabs became a secondary objective of the study. Further details of the methodology and results of the study are available in the full technical report for the project (Wahle et al. 2004).

The study was centered on the disposal grounds at the Rockland disposal site at the mouth of Penobscot Bay, Maine, approximately mid-way between Rockland Harbor and North Haven Island (Fig. 1). A buoy labeled 'DG' located at $44.11933^{\circ} \mathrm{N}, 69.00170^{\circ} \mathrm{W}$ marked the disposal site. Previous disposal events have contributed to the mud, sand, and gravel mixture that naturally occur in this area. Water depths at the site range from 65 to $75 \mathrm{~m}$ below mean low water, and the area is subject to north-south trending tidal currents, ranging from 0.1 to $14.5 \mathrm{~cm} \mathrm{~s}^{-1}$ over the course of the study. Between 1985 and 2001 there were 585 disposal events (i.e. barge loads), amounting to $586050 \mathrm{~m}^{3}$ of material. Material was dredged using a clamshell dredge and was placed in and disposed from a split-hull barge. Disposal activity during this study commenced on 18 November 2002 and continued beyond the time frame of the study. Disposal was scheduled during these late fall and early winter months to avoid conflicts with active lobster fishery in the summer and fall and with frozen harbors in the winter and spring. Between 18 November and 20 December there were 81 disposal events, totaling $57105 \mathrm{~m}^{3}$ of material.

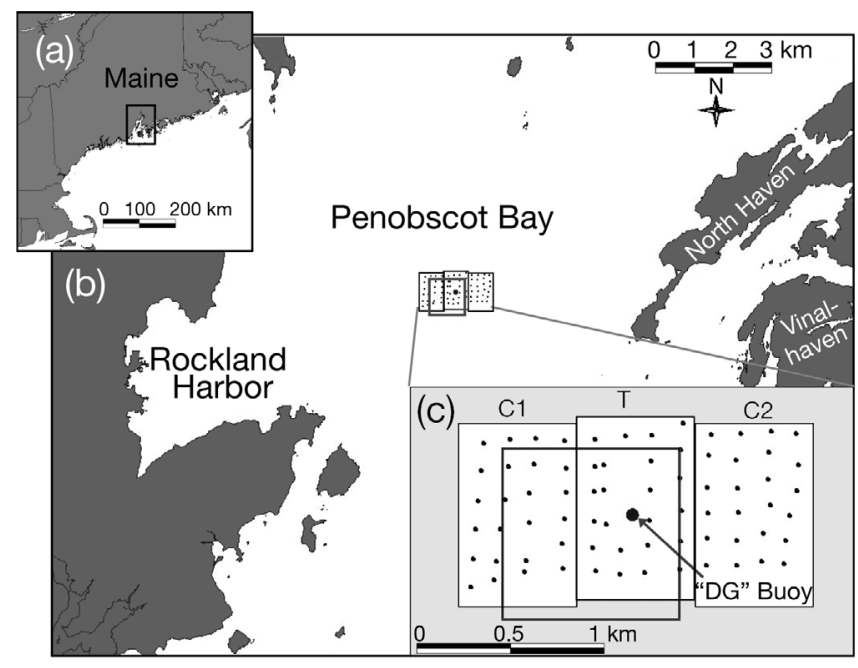

Fig. 1. (a) Location of Penobscot Bay in Maine. (b) Location of Rockland disposal site (grey outline) and study area (Areas C1, C2 and T) within Penobscot Bay. (c) Study area was centered on the disposal grounds buoy ('DG', $\bullet$ ), the designated location of disposal events during the study. A spatially referenced array of 72 lobster traps (small dots) was spread uniformly over 3 equal experimental areas: a treatment area ( $\mathrm{T}$ ), and 2 flanking control areas (C1, C2) less likely to be impacted given the north-south tidal flow
The site is located in a common transit route with considerable shipping traffic. Although the area is also heavily fished for lobsters during the warm months, fishing activity was on the decline at the beginning of the study and little to no fishing gear was present in the area by the end of the study.

Experimental design. Timing of study: The timing of disposal was set by the US Army Corps of Engineers in consultation with the Maine Department of Marine Resources. Lobsters inhabiting bays and estuaries during the summer are widely known to move to deeper water during the late fall, when harvesters either remove their traps for the season or move them to deeper water to continue into the early winter months (Watson et al. 1999). Therefore, we evaluated the effects of disposal on lobsters and crabs present in this area during late autumn. Our trapping project began 1 November 2002, and sediment disposal began on 18 November and continued into January 2003, well past the end point of our study on 19 December 2002.

Seabed mapping: Side-scan sonar surveys of the experimental area were conducted on 2 occasions: once before and once after a period of disposal activity (14 November and 20 December 2002, respectively). The surveys utilized identical equipment, data collection, and post-processing protocols as described by Dunnington et al. (2005).

The resulting geo-referenced images were imported into ESRI's ArcView ${ }^{\circledR} 3.2$ GIS software to conduct a before-after comparison. The trap array and 3 study areas were overlaid as constant reference points. In addition, each of the 3 study areas was divided into 6 subsections and assigned a unique identifier so that corresponding subsections in the before and after images could be enlarged (1:2100) and compared visually. This comparison was a somewhat subjective analysis; nonetheless, criteria for noting substrate changes were established. First, in corresponding before and after subsections, obvious differences in seabed features (anomalies) were noted. Second, the grain size composition of each subsection was classified into 1 of 3 categories: (1) fine sediment, (2) coarse gravel and boulder, and (3) a mix of the two. Our interpretation of sediment types and alterations from sidescan images was verified by the Marine Geology Working Group at the University of Maine's Department of Geological Sciences.

Trapping protocol: To capture both the spatial and temporal effects of the dredged material disposal on lobster and crab catch rates, we employed a beforeafter-control-impact (BACI) experimental design (e.g. Underwood 1991, Smith et al. 1993, Stewart-Oaten 1993). We set 72 baited lobster traps in a $6 \times 12$ grid centered on the DG buoy and spread over a $0.9 \times$ 
$1.7 \mathrm{~km}$ area $\left(1.53 \mathrm{~km}^{2}\right.$, Fig. 1). Traps were thus spaced approximately $180 \mathrm{~m}$ apart on the $\mathrm{N}-\mathrm{S}$ axis and $155 \mathrm{~m}$ apart on the E-W axis, with the exception that 3 traps in one of the central columns were offset from this pattern by approximately $100 \mathrm{~m}$ to the west to avoid damage from tug and barge traffic moving in and out of the disposal site to unload dredged material. Each trap location was spatially referenced with a differential GPS (global positioning system) using a North Star 951 XD unit with a precision of $\pm 3 \mathrm{~m}$. The array was arbitrarily divided into 3 equal areas: a treatment area $(\mathrm{T})$, where disposal impacts were likely to occur, and 2 flanking control areas (C1, C2), where no disposal activity was planned. While it would not generally be desirable to situate control sites so close to the impacted site, the advantage of having contiguous treatment and control areas was in enabling mapping of the extent of the impacted area.

We used standard commercial lobster traps of vinylcoated wire mesh $(1.2 \times 0.6 \times 0.4 \mathrm{~m})$, modified to prevent the escape of sub-legal lobsters $(<83 \mathrm{~mm}$ carapace length). Traps were hauled and reset at the same locations twice a week and then on a weekly basis from 1 November until 19 December 2002. Traps were baited with 3 or 4 salted herring in a bait bag. The bait was changed each time traps were hauled. Traps were returned to within approximately $20 \mathrm{~m}$ of the original geo-referenced location. Some 18 traps were lost over the course of the study, resulting in minor loss of data. In most cases, traps were replaced before the next sampling occasion.

For each trap, we counted and measured lobsters and crabs in the catch. Lobsters were tagged with temporary self-locking 'cinch-up' and 'cable tie' tags. Due to the large volume of crabs, we assessed size composition on 2 sampling dates when we measured the entire contents of haphazardly selected traps. Because crabs were not initially a focus of the impact study, we did not tag them. All lobsters and crabs were released at the same trap location where they were caught.

We acknowledge that by deploying an array of baited traps on the seabed we may have attracted lobsters or crabs to the area, thereby biasing estimates of abundance. However, bait was uniformly distributed among all traps in the array, and our primary aim was to evaluate disposal impacts by comparing the relative catch rates inside and outside the impacted area.

The lobster tagging component of the study is described in detail in Wahle et al. (2004) and is not included here because of the relatively few returns. Nonetheless, the resultant analysis was important in confirming that changes in lobster catch reflected change in abundance.
Fine-scale spatial analysis of catch. Using ESRI's ArcView ${ }^{\circledR} 3.2$ GIS software, catch data for each trap were linked to latitude and longitude positions of the traps. The resulting spatially explicit catch data enabled us to map the time series of distributions of lobster and crab catches over the study area as described by Wahle et al. (2004).

Statistical analysis of catch. In the analysis of catch rates, we report catch-per-haul as the response variable, as opposed to catch-per-day (i.e. catch per haul / soak time in days). To use the latter would have assumed a linear relationship between size of the catch and soak time that may not be valid, especially in cases where traps may fill to capacity; in our case, most likely with crabs. If the catch-per-day metric is used and traps fill to capacity, catch rate in the days before the trap fills may be underestimated. Nonetheless, statistical analysis using the 2 expressions of catch rate did not alter the major conclusions of the study regarding lobster catch.

We employed a single-factor ANOVA to test the null hypothesis that the proportional change in catch of lobsters and crabs after the onset of disposal was no greater in the treatment area than in the adjacent control areas. We used proportional changes as the response variable in this case to standardize for preexisting area-specific differences in absolute catch, which were less important to the assessment of disposal impacts. To determine proportional change in catch for each trap, we subtracted the average catch per haul after the onset of disposal from the average pre-disposal catch; this difference was then calculated as a proportion of the pre-disposal average. Thus, if the average catch for a trap declined after disposal began, we would record a negative proportional change.

Based on the footprint of newly disposed sediment, we further refined our analysis of catch impacts to the 8 traps at the center of the treatment area that were most likely to be impacted, along with their counterparts in the 2 reference areas $(\mathrm{C} 1, \mathrm{C} 2)$ to balance the comparison with the same number of traps per area. This also provided further spatial separation between the areas being analyzed, ensuring greater independence.

Data were rank transformed in order to satisfy the assumptions of the ANOVA. A Bartlett's test was used to confirm that variances were homogeneous, and a Shapiro-Wilks' test confirmed the assumption of normality. Although the 3 areas were spatially contiguous, our results do not suggest that catch rates in any single area influenced the catch rates in another, and we found no evidence that the assumption of independence was violated. If the ANOVA resulted in a significant treatment effect (at $\mathrm{p}<0.05$ ), we employed a SNK (Student-Newman-Keuls) post hoc test to make pair- 
wise comparisons of proportional catch in the 3 experimental areas. Significance of the post hoc test was then set at $\mathrm{p}<0.01$.

\section{RESULTS}

\section{Habitat impacts}

The side-scan sonar survey conducted prior to the onset of disposal events revealed a pre-existing heterogeneity and a number of prominent features on the seabed. Previous disposal events may have contributed to the seabed structure we observed (Fig. 2a). In general, sediments on the western side of the study area consisted of coarser material than those on the eastern side (Fig. 2b). The mottled, high reflectance area directly west of the DG buoy corresponded with the location of prior disposal events over the years between 1985 and 2000. The more uniformly dark, high reflectance area directly below the buoy corresponded with the disposal locations during 2001. The

(a)

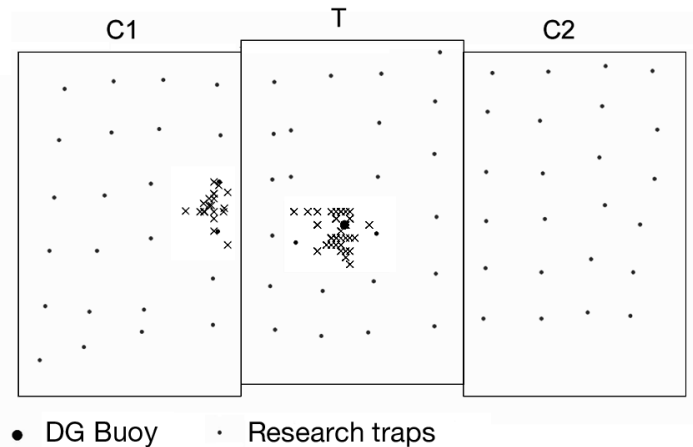

(b)

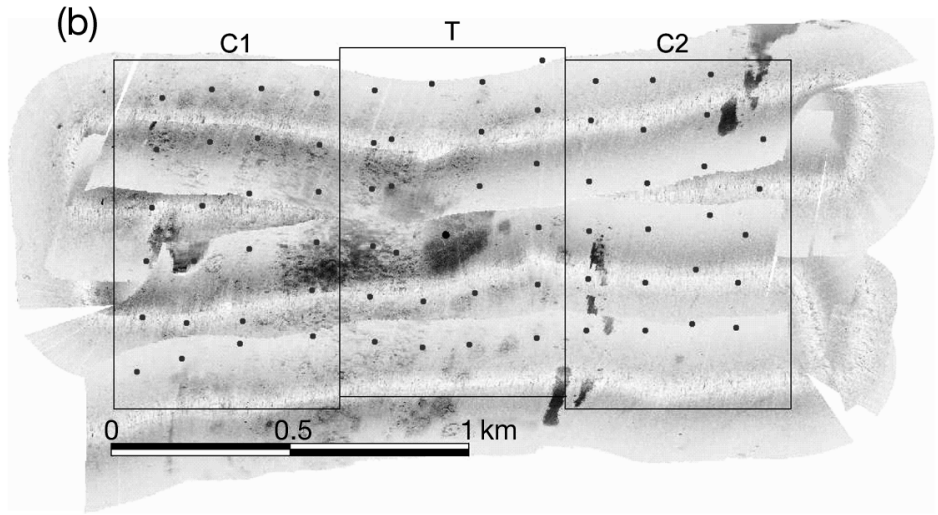

Fig. 2. (a) Study area indicating the location of disposal from 1999 to 2001, for which GPS positions were taken ( $\times$ ). (b) Sidescan sonar survey of study area conducted on 14 November 2002, immediately prior to the onset of disposal activity during this study. Dark mottled areas correspond to previous disposal locations and likely represent coarser sediments remaining after winnowing by tidal action. Striping across the image is distortion of the side-scan signal difference in appearance between the 2 disposal mounds is likely due to differing grain size and degrees of reworking and winnowing. Other prominent features included a large rock outcrop just inside the western border of Area C1 and a non-contiguous vein of undetermined high-reflectance material trending northeast to southwest through Area C2. All of these features, with the exception of the latter, were also described in a previous disposal area monitoring report (SAIC 2001).

The post-disposal side-scan sonar images revealed an area of recently deposited low reflectance soft sediment roughly centered on the DG buoy that was not present in the pre-disposal images (Figs. $3 \& 4$ ). This feature corresponds with the locations of disposal events since the study began (Fig. 3a). Combining the extent of the new mound of soft sediment with the known locations of most recent disposal events, we delineated a conservative estimate of the impacted area that covers $7 \%\left(44170 \mathrm{~m}^{2}\right)$ of the treatment area (Fig. 4c). A less conservative estimate of the outer limits of the impacted area incorporated more subtle differences in substrate between the preand post-disposal side-scan images. Including this outer limit expands the impacted area to $18 \%$

(a)

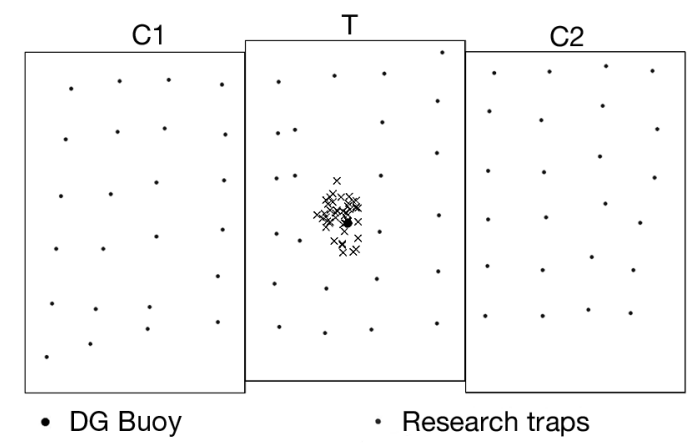

(b)

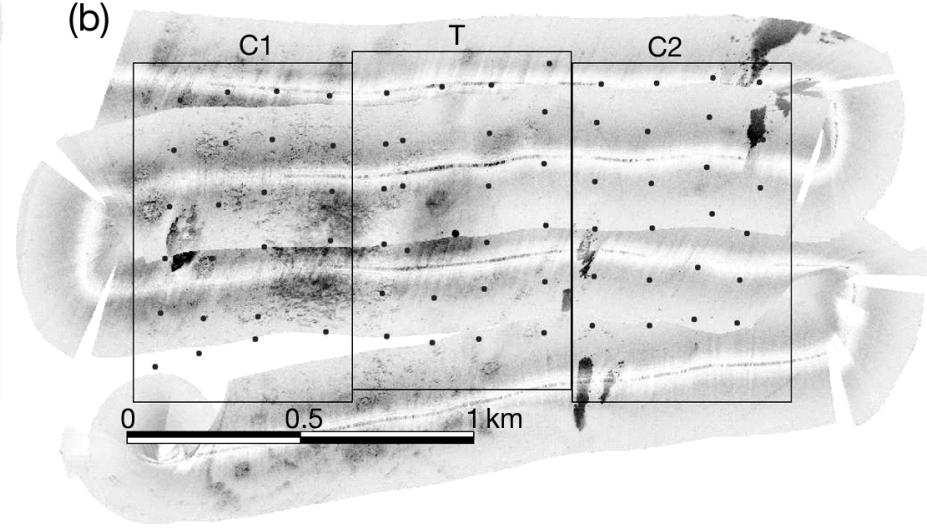

Fig. 3. (a) Study area indicating location of disposal events during this study between 18 November and 21 December $2002(\times)$. (b) Side-scan sonar survey of study area conducted on 20 December 2002 after several weeks of disposal activity 
(a)

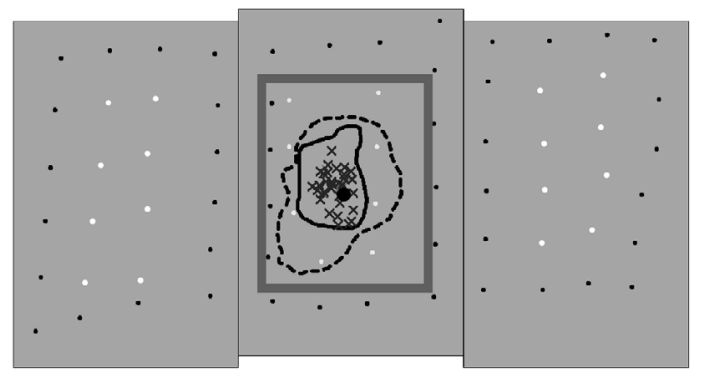

NImpact area - conservative $\therefore$ ímpact area - outer limit

$\times$ Drop locations - 11/18/02-12/18/02

(b)

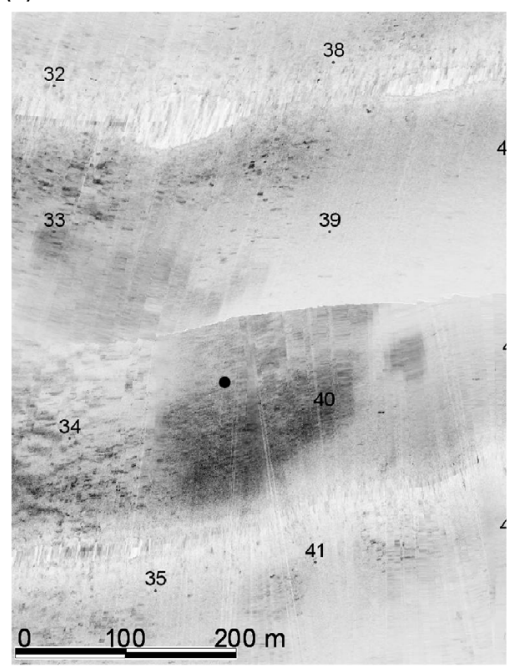

- Most impacted trap comparison

- Remaining traps

- Disposal area buoy

(c)

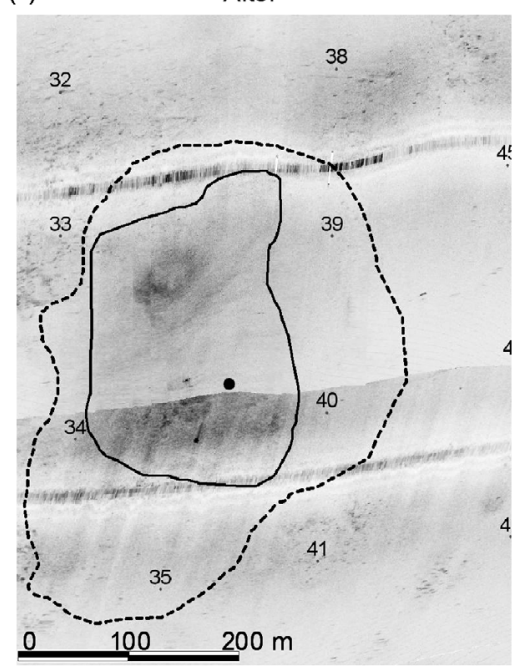

Fig. 4. (a) Study area indicating interpreted areas of impact around the disposal events that occurred during this study. Initial statistical analysis of impacts on catch included all traps; secondary analysis compared the 8 central traps (white dots) within Area $\mathrm{T}$ (that were most likely to be impacted) with their counterparts in Areas C1 and C2. Area within thich grey line enlarged as side-scan sonar images taken (b) before and (c) after most recent disposal events. Area within solid inner line is conservative estimate of impacted area; area within dashed outer line includes more subtle substrate differences

$\left(108881 \mathrm{~m}^{2}\right)$ of the treatment area. Because the impacted area was so limited, we narrowed our analysis to the most central traps in the portion of the treatment area most likely to be impacted (Fig. 4a). This became the basis for conducting the secondary analysis of trap catch impacts in the more restricted area.

\section{Catch patterns}

A total of 1056 lobsters Homarus americanus were caught over the $7 \mathrm{wk}$ study period. The mean carapace length was $83 \mathrm{~mm}$ ( $\mathrm{SD}=9 \mathrm{~mm}$ ). We also caught 28610 crabs, all of which were Cancer irroratus, except for 6 green crabs Carcinus maenas. The green crabs appeared late in the season and are believed to have originated from the disposal sediments. The mean $C$. irroratus carapace width was $108 \mathrm{~mm}(\mathrm{SD}=16)$.

The spatial pattern of the catch within each of the 3 areas reveals the detail of the contrasting response of lobsters and crabs to the disposal event (Figs. 5 \& 6). Initial lobster catches were highest in Area C1 and were concentrated in the area of the older of the 2 disposal mounds identified in the side-scan sonar analysis (Fig. 5). Lobster catches diminished to a uniformly low level in all areas by early December. While crab catches throughout most of the study were highest in Area C2, during the last 3 to 4 trapping occasions crab catches became increasingly concentrated at the location of the recently disposed material (Fig. 6).

Grouping the data by area and parsing it into pre- and post-disposal periods further reveals the contrasting and somewhat complimentary response of crabs and lobsters to the disposal event (Fig. 7). Crab catches were roughly 10 -fold higher than lobster catches. Lobster catch rates tended to be higher in the western area (C1) with coarser substrate, whereas the crab catch tended to be higher to the east (C2) in finer grained substrate. During the course of the study, lobster catch declined. In contrast, the crab catch increased mostly in the treatment area, less so in Area C2, and remained nearly constant in Area C1.

For lobsters there was no significant difference in proportional change in catch among the 3 areas (Fig. 8, Table 1); in all 3 areas the catch declined by 36 to $42 \%$. In contrast, for crabs there was a significant $140 \%$ increase in catch in Area T, whereas crabs in the 2 control areas (C1, C2) increased by lesser amounts of 16 and $58 \%$, respectively (SNK-test crabs, $\mathrm{T}>\mathrm{C} 2>\mathrm{C} 1$, $\mathrm{p}<0.01$ ). Secondary analysis of the catch in the 8 central traps of each area suggested more pronounced disposal impacts, both for lobsters and crabs, than in the initial all-inclusive analysis (Fig. 8b, Table 1). While proportional changes in the catch of the 8 central traps of the control areas remained largely unchanged, lobster declines in the treatment area went from 36 to $75 \%$, while increases in the crab catch grew from 140 
to $218 \%$. Despite these apparently more pronounced differences, the statistical significance of the treatment effect was weakened slightly for both species, most likely because of the loss of statistical power associated with a smaller sample size (Table 1 ; SNK-test crabs: $\mathrm{T}>\mathrm{C} 1, \mathrm{p}<0.01 ; \mathrm{T}>\mathrm{C} 2, \mathrm{p}<0.01 ; \mathrm{C} 1=\mathrm{C} 2, \mathrm{p}>0.01)$.

\section{DISCUSSION}

The conflict of uses of the ocean (e.g. fishing and disposal) will undoubtedly become ever more pronounced with increasing human populations on land and our demand for marine products and services. It is clear, then, that developing practical tools that quantify the consequences of these uses will be important for the future of natural resource management.

Employing spatially referenced trap grids enabled us to monitor previously unstudied impacts of dredge spoil disposal on lobsters Homarus americanus and crabs Cancer irroratus. Although these animals comprise economically significant fisheries in the area, it is perhaps not surprising that they have been omitted from previous disposal impact studies. The depth of the ocean floor at the disposal site is too great for diver surveys and could only, therefore, be moni-
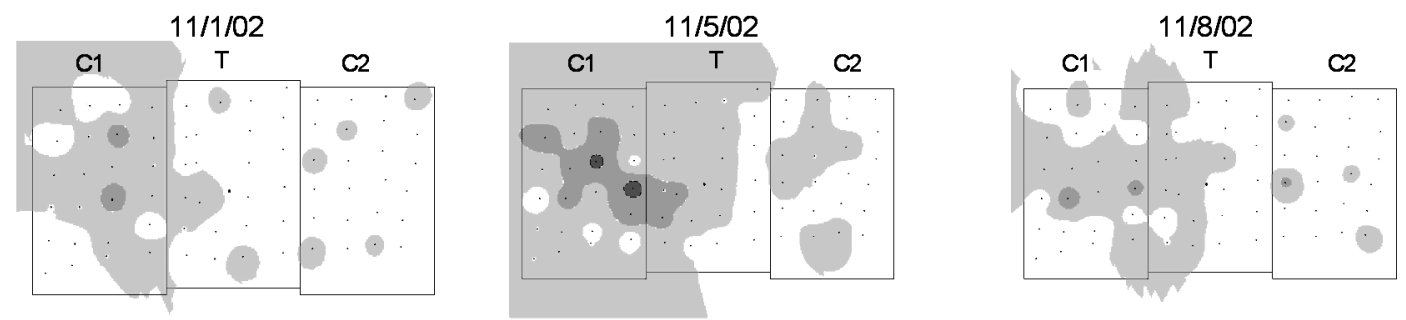

$11 / 12 / 02$

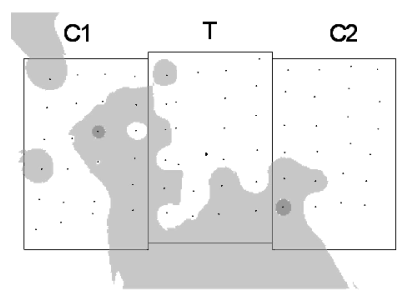

$11 / 26 / 02$

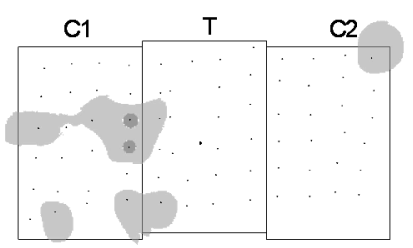

$12 / 16 / 02$

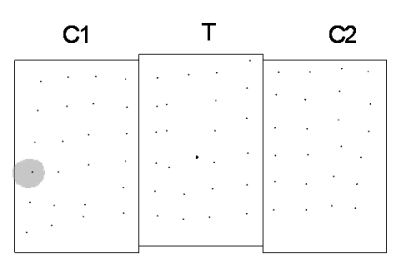

$11 / 15 / 02$

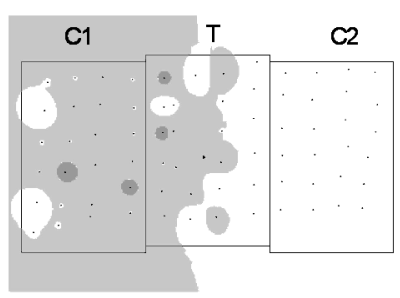

$12 / 4 / 02$

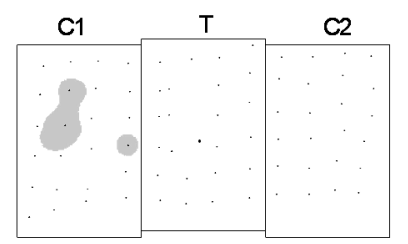

$12 / 19 / 02$

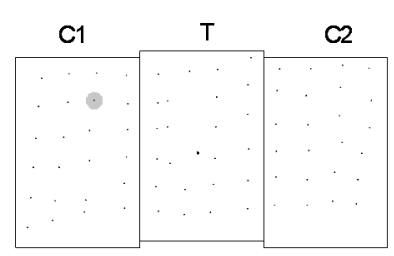

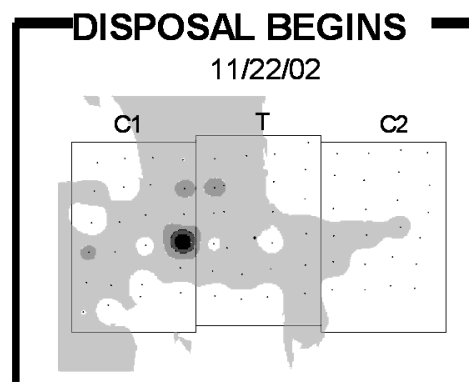

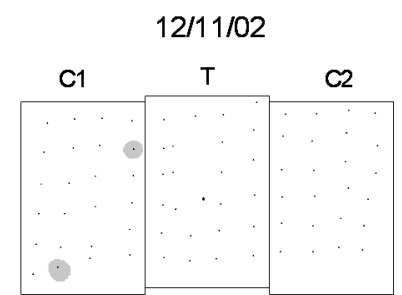

Lobster Catch per Haul

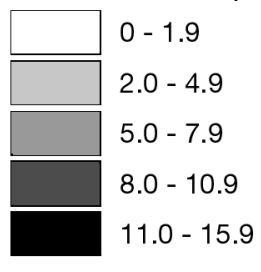

Fig. 5. Homarus americanus. Time series of spatial patterns in lobster catch. Catch standardized to catch per haul. Soak times ranged from 3 to $8 \mathrm{~d}$. Dates given as $\mathrm{mm} / \mathrm{dd} / \mathrm{yy}$ 
$11 / 5 / 02$

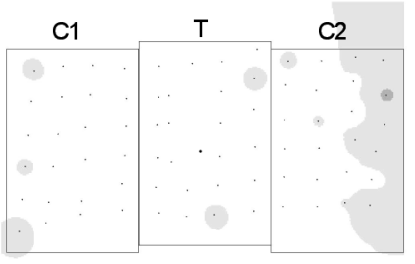

$11 / 12 / 02$

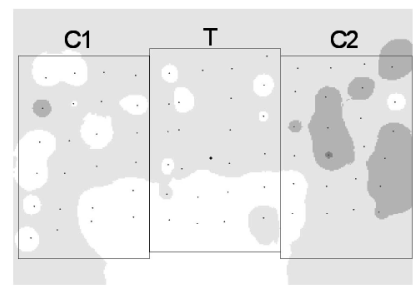

$11 / 26 / 02$

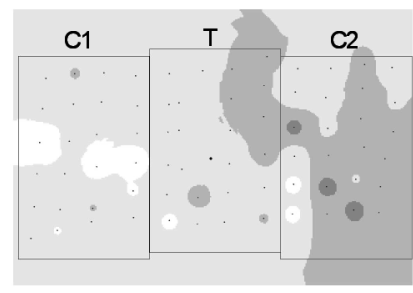

$12 / 16 / 02$

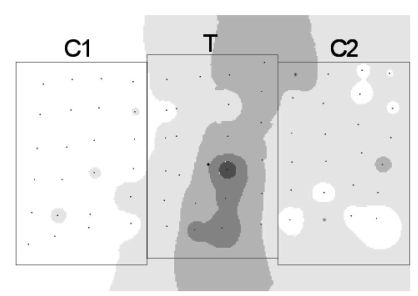

$11 / 15 / 02$

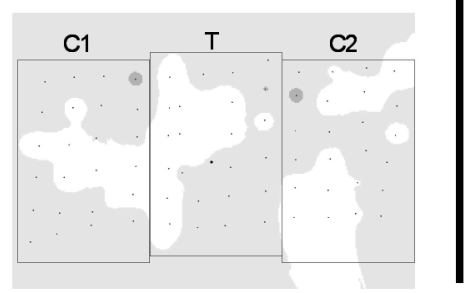

$12 / 4 / 02$

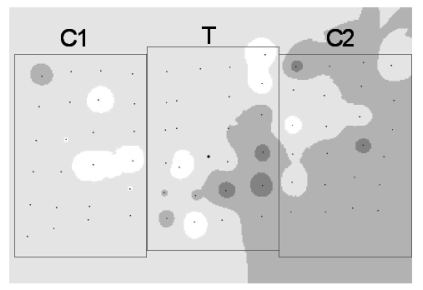

$12 / 19 / 02$

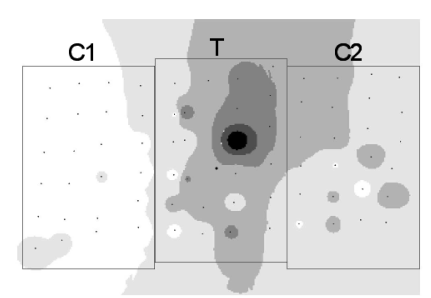

$11 / 8 / 02$

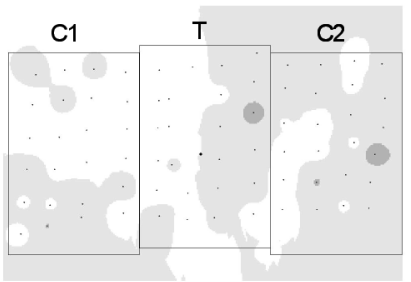

$11 / 22 / 02$

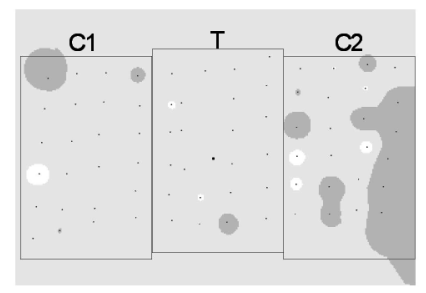

$12 / 11 / 02$

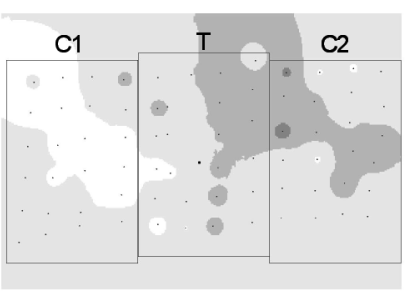

Crab Catch per Haul

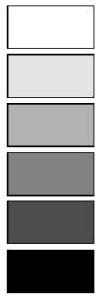

$0-31.9$

$32.0-63.9$

$64.0-95.9$

$96.0-127.9$

$128.0-159.9$

$160.0-192$

Fig. 6. Cancer irroratus. Time series of spatial patterns in crab catch. Catch standardized to catch per haul. Soak times ranged from 3 to $8 \mathrm{~d}$. Dates given as mm/dd/yy. Note difference in catch scale compared to lobsters (Fig. 5)

tored visually with submersibles, remotely operated vehicles, or drop cameras. Trawling is widely used to census lobster populations, but would be inappropriate at a disposal site where steep changes in topography limit the functionality of this gear. These methodologies can be prohibitively expensive for this type of study, and in any case only provide a snap shot of abundance. Spatially referenced trap grids can be a cost-effective, easy-to-deploy tool that integrates abundance over time and may be especially useful in detecting local environmental impacts on mobile organisms that may occur at low population densities.
This study benefited greatly from the collaboration and cooperation with the Penobscot Bay fishing industry. Local harvesters loaned the traps and buoy colors for the study. This cooperation enabled us to maintain our presence on the fishing grounds without losing traps. Furthermore, data generated by traps in the form of maps of catch rates were an effective tool for communicating results to non-scientist stakeholders.

The disposal events during this study resulted in a conspicuously altered benthic habitat, consisting of a low-relief mound of accumulated sediments in the immediate area of the disposal buoy. The uniformity of the mound suggested that it was composed of fine 

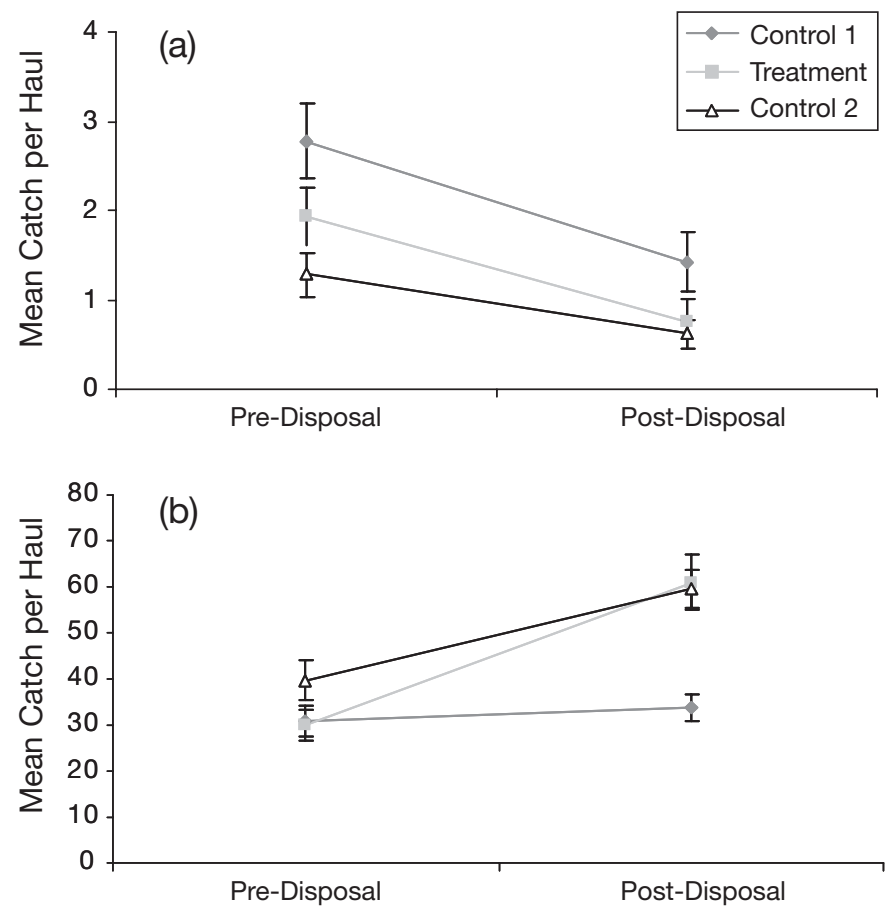

Fig. 7. Homarus americanus, Cancer irroratus. Pooled mean catch per haul ( $\pm 1 \mathrm{SE}$ ) of (a) lobsters and (b) crabs in each study area before and after the onset of disposal
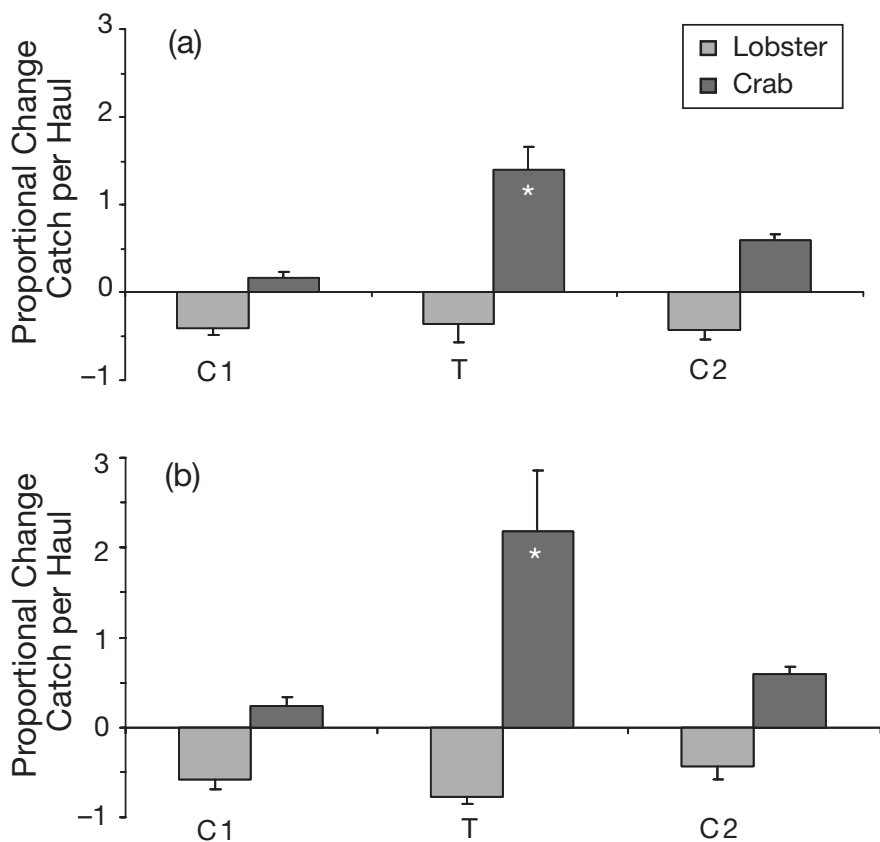

Fig. 8. Homarus americanus, Cancer irroratus. Proportional change in crab and lobster catch per haul ( \pm 1 SE) (a) for all traps and (b) for the central traps within each study area. Results of statistical analysis in Table 1. Asterisk indicates statistically significant treatment as determined by ANOVA followed by post hoc pairwise comparisons (SNK tests, $\mathrm{p}<0.01$ ) sediments and that coarser material, if there was any, had not yet been exposed by the winnowing of tidal currents. Any more subtle substrate effects that may have existed over a larger area were not detectable from our side-scan sonar images.

Adverse impacts of disposal on lobsters appear to have been negligible during these disposal events, most likely because sediment disposal occurred at a time when lobsters were leaving the bay on their annual outward migration. This agrees with the general observation that in temperate waters the impacts of sediment disposal on benthic organisms is minimized during autumn months, when organisms are absent or dormant, recruitment is low, and water quality is more favorable than during the warmer months (Van Dolah 1984).

We believe our interpretation that the effect of sediment disposal on lobsters was negligible, but strongly positive on crabs is robust to potentially confounding factors that may suggest alternative explanations. Although baited traps may attract lobsters and crabs to the area, thereby enhancing population densities, baiting was uniform across the entire study area, including both Areas C1 and C2 and Area T, and therefore does not explain the enhanced catches of crabs we observed in Area T. Similarly, we would be hard pressed to explain the spatial differences in crab catch that emerged over the course of the season on the basis of differences in catchability. Further, although the catchability of lobsters can decline as waters cool (Flowers \& Saila 1972), our mark-recapture analysis for tagged lobsters in this study (Wahle et al. 2004) suggests that this was not the case.

The relatively high lobster catch rates associated with the coarser sediments of the study area during the early part of the study likely relate to the behavioral preference for pre-existing shelter (Lawton \& Lavalli 1995). By December, lobster catch rates had become very low, so that the decline in lobster catch in the treatment area was not significantly greater than in the 2 control areas.

Table 1. Homarus americanus, Cancer irroratus. Single-factor ANOVA results for proportional change in lobster and crab catch per haul for the entire trap array and the 8 central traps. Both lobster and crab data were rank transformed prior to analysis to satisfy assumptions of homogeneity of variance among treatments

\begin{tabular}{|lccc|}
\hline & $F$ & $\mathrm{df}$ & $\mathrm{p}$ \\
\hline Lobsters & & & \\
All traps & 1.892 & 2,69 & 0.1585 \\
Central traps & 1.837 & 2,21 & 0.1840 \\
Crabs & & & \\
All traps & 34.382 & 2,69 & $<0.00001$ \\
Central traps & 15.343 & 2,21 & 0.00008 \\
\hline
\end{tabular}


If an interaction between lobsters and crabs in traps was driving the spatial catch pattern (e.g. Richards \& Cobb 1986, Miller \& Addison 1995), we might expect to see a complementary spatial pattern of lobster and crab catches. Admittedly, at the onset of the study, before disposal began, the catch on the western side of the area was dominated by lobsters and the eastern side by crabs, but this pattern did not persist. During the disposal period, lobsters became uniformly rare across all areas, while the crab catch increased significantly only in the area immediately surrounding the disposal site. While we cannot entirely rule out the possibility of a crab-lobster interaction, it is insufficient to explain the catch patterns we recorded after the onset of sediment disposal.

The dramatic increase in catch rate of rock crabs in the immediate area of the disposed sediments suggests that they were attracted to the new material. Given its source, the newly disposed sediments contained a richer concentration of invertebrates and other organic material that could have attracted crabs (Reilly \& Saila 1978, Stehlik 1993, Wilber \& Clarke 1998, SAIC 2001). The spike in crab catch at the disposal site occurred during a more gradual general increase in crab catch over the entire study area. It is likely that crabs were immigrating to the area during the period. Prior surveys of rock crabs in the Gulf of St. Lawrence also indicate a seasonal movement into soft sediments in nearshore waters during the fall (Gendron \& Cyr 1994). In keeping with that observation, prior to the disposal events, the crab catch was somewhat higher at the eastern end of our study area and may reflect a tendency to associate with finer sediments.

However, these results should not be taken to infer that sediment disposal would not impact lobsters during the warmer season, when they are more abundant in Penobscot Bay. During the height of the summer fishing season, lobster densities at 4 other locations in Penobscot Bay have been estimated by the same methods to be as high as 60000 ind. $\mathrm{km}^{-2}$, and support catch rates averaging from 10 to 30 lobsters per trap (Dunnington et al. 2005). Disposal during the warmer months could potentially bury a considerable number of lobsters. Seasonal movements of lobsters are well documented throughout the species range (Munro \& Therriault 1983, Campbell \& Stasko 1986, Watson et al. 1999) and may create the opportunity for safe sediment disposal. These movements tend to correlate with seasonal warming and cooling, and changes in turbulence and salinity in nearshore waters. The decline in lobster catch at the disposal site and reports of tagged lobsters in deeper offshore waters (Wahle et al. 2004) are consistent with an offshore migration during the fall.

Disposal of sediment, gravel, and sludge on the seabed can have both negative and positive effects on resident fauna depending on a range of variables. The most important among these include the volume and type of sediment, ambient temperature, water depth, oceanographic conditions, depth of overburden deposited, time period of burial, and adaptations of present organisms to the 'dynamic sedimentary environment' (Van Dolah 1984, Smith \& Rule 2001, CruzMotta \& Collins 2004). Although none of the aforementioned studies evaluated the effects of these variables on lobsters or crabs, other studies have found that placement of cobbles and boulders in experimental reefs of various sizes have positive effects on local lobster densities via immigration and larval settlement (Wahle \& Incze 1997, Castro et al. 2001). Conversely, discontinuing disposal of fine, organically rich sediments can have a positive effect. For example, the discontinued disposal of fine sediments and sewage sludge at a site in the New York Bight was reported to have favored the return of lobsters to the area and had little short-term impact on the distributions of several crab species, including Cancer irroratus (Pikanowski 1992).

These reports and our observations are generally consistent with prior work on the habitat preferences of the American lobster and rock crab. Although the 2 species broadly overlap in habitat use, lobsters tend to prefer to shelter in coarse gravel and boulder substrates, especially at the time of larval settlement and during early benthic life. As lobsters grow, shelter fidelity relaxes, movements become wider ranging, and they become entrained in seasonal inshore-offshore movements, but continue to prefer pre-existing shelter throughout life (see review by Lawton \& Lavalli 1995). The rock crab, by contrast, is less discriminating about the quality of settlement habitat (Palma et al. 1998), although it tends to concentrate in rocky habitats as a larger juvenile and ranges widely as an adult (Gendron \& Cyr 1994). Reports of movements are limited, but where movement has been studied, adult rock crabs tend to migrate into shallow soft sediment during the fall, where they bury themselves during the coldest months (Gendron \& Cyr 1994). Thus, previously described differences in seasonal activity and migration patterns of the lobster and crab largely explain the difference in our observations of how sediment disposal impacted them.

An assessment of longer-term impacts was beyond the scope of this study. Dredged sediments from harbors and channels can contain pollutants that are toxic to marine organisms over longer time scales (Kester et al. 1983). On the other hand, the relatively rich biotic material in these sediments and the assemblage of fauna that invades it after deposition could enhance food availability (Wilber \& Clarke 1998). In the case of prior disposal events at the Penobscot Bay disposal site, however, sediments were chemically screened 
before disposal was approved (USACE 1992). These potential longer-term effects remain undetermined for lobsters and crabs that inhabit or move through the disposal site.

In conclusion, our approach suggests that spatially referenced, trap-based information, along with seabed mapping, can be a useful tool in assessing the impacts of local environmental perturbations to mobile benthic invertebrates such as lobsters and crabs. On the basis of this approach, we conclude that disposal events at the Rockland disposal site resulted in localized habitat alteration in the form of a mound of soft sediments. This habitat alteration affected lobsters and crabs differently, largely because of differences in their seasonal pattern of habitat use and migration. Sediment disposal had no detectable effect on lobster catch or estimated abundance, most likely because of the low population densities residing in coastal embayments in late autumn. These results therefore support the assertion that disposal impacts to the valuable lobster fishery may be minimized at this time. Because lobsters tend to associate with coarse, shelter-providing substrates, winter disposal of coarse-grained dredged sediments may even provide an opportunity to enhance lobster populations. In contrast, rock crab catch increased significantly in the immediate area of the newly deposited sediment. Although we cannot rule out the possibility that crab catches were suppressed, while lobsters were abundant in the area, the spatial pattern of the crab catch suggests that crabs were attracted to the newly deposited sediments rich in invertebrates and other food items.

Acknowledgements. This project was supported by funds from the US Army Corps of Engineers, New England District, through the Maine Sea Grant Program. We acknowledge vessel support aboard the RV 'Alice Siegmund' and assistance in gear rigging by $\mathrm{C}$. Roberts of the Island Institute. We thank lobster fisherman, W. Day, of Vinalhaven for the lease of lobster traps. A. Gontz, of the Marine Geology Working Group, University of Maine, conducted side-scan sonar surveys and image post-processing. The Island Institute provided facilities for GIS analysis of fine-scale spatial patterns. The manuscript was improved by comments from G. French.

\section{LITERATURE CITED}

Bell MC, Eaton DR, Bannister RCA, Addison JT (2003) A mark-recapture approach to estimating population density from continuous trapping data: application to edible crabs, Cancer pagurus, on the east coast of England. Fish Res 65:361-378

Bennett AF (1990) Habitat corridors and the conservation of small mammals in a fragmented forest environment. Landsc Ecol 4(2/3):109-122

Campbell A, Stasko AB (1986) Movements of lobsters (Homarus americanus) tagged in the Bay of Fundy, Canada. Mar Biol 92:393-404
Castro K, Cobb JS, Wahle RA, Catena J (2001) Habitat addition and stock enhancement for American lobsters, Homarus americanus. Mar Freshw Res 52:1253-1261

Cruz-Motta JJ, Collins J (2004) Impacts of dredged material disposal on a tropical soft-bottom benthic assemblage. Mar Pollut Bull 48:270-280

Dunnington MJ, Wahle RA, Bell MC (2005) Trap-based mark-recapture methods integrated with seabed mapping evaluate local American lobster population dynamics. Mar Freshw Res 39:1253-1276

Flowers JM, Saila SB (1972) An analysis of temperature effects on the inshore lobster fishery. J Fish Res Board Can 29:1221-1225

Frusher SD, Hoenig JM (2003) Recent developments in estimating fishing and natural mortality and tag reporting rate of lobsters using multi-year tagging models. Fish Res 65:379-390

Gendron L, Cyr C (1994) Distribution bathymetrique et saisonniere du crabe commun (Cancer irroratus) au large d'Anse-a-Beaufil, Québec. Rapp Tech Can Sci Halieut Aquat 2014:1-53

Grigalunas T, Opaluch JJ, Luo M (2001) The economic costs to fisheries from marine sediment disposal: case study of Providence, RI, USA. Ecol Econ 38:47-58

Harvey M, Gauthier D, Munro J (1998) Temporal changes in the composition and abundance of the macro-benthic invertebrate communities at dredged material disposal sites in the Anse a Beaufils, Baie des Chaleurs, eastern Canada. Mar Pollut Bull 36:41-55

Jackson JBC, Kirby MX, Berger WH, Bjorndal KA and 15 others (2001) Historical overfishing and the recent collapse of coastal ecosystems. Science 293:629-638

Jones AR (1986) The effects of dredging and spoil disposal on macrobenthos, Hawkesbury Estuary, NSW. Mar Pollut Bull 17(1):17-20

Kester DR, Ketchum BH, Duedall I, Park PK (1983) Wastes in the ocean, Vol 2. John Wiley \& Sons, New York

Lawton P, Lavalli K (1995) Postlarval, juvenile, adolescent, and adult ecology. In: Factor JR (ed) Biology of the lobster, Homarus americanus. Academic Press, New York, p 47-88

Lubchenco J, Olsen AM, Brubaker LB, Carpenter SR and 12 others (1991) The sustainable biosphere initiative: an ecological research agenda: a report from the Ecological Society of America. Ecology 72(2):371-412

Miller RJ, Addison JT (1995) Trapping interactions of crabs and American lobster in laboratory tanks. Can J Fish Aquat Sci 52:315-324

Munro J, Therriault JC (1983) Seasonal migrations of lobster (Homarus americanus) between the coast and the lagoons of the Magdalen Islands. Can J Fish Aquat Sci 40:905-918

Palma A, Wahle RA, Steneck RS (1998) Different early postsettlement strategies between American lobsters Homarus americanus and rock crabs Cancer irroratus in the Gulf of Maine. Mar Ecol Prog Ser 162:215-225

Peterson CH, Estes JA (2001) Conservation and management of marine communities. In: Bertness MD, Gaines SD, Hay ME (eds) Marine community ecology. Sinauer Associates, Sunderland, MA, p 469-507

Pikanowski RA (1992) The effects of ocean disposal of sewage sludge on the relative abundance of benthic megafauna. Chem Ecol 6:199-212

Reilly PN, Saila SB (1978) Biology and ecology of the rock crab, Cancer irroratus Say, 1817, in southern New England waters (Decapoda, Brachyura). Int J Crustac Res 34(2):121-140

Richards A, Cobb JS (1986) Competition for shelter between lobsters (Homarus americanus) and jonah crabs (Cancer 
borealis): effects of relative size. Can J Fish Aquat Sci 43: 2250-2255

Rivers-Moore NA, Samways MJ (1996) Game and cattle tramping, and impacts of human dwellings on arthropods at a game park boundary. Biodivers Conserv 5: 1545-1546

SAIC (Science Applications International Corporation) (1989) Monitoring cruise at the Rockland disposal site, July 1989. Disposal Area Monitoring System Contribution 83, US Army Corps of Engineers, New England District, Waltham

SAIC (Science Applications International Corporation) (2001) Monitoring cruise at the Rockland disposal site, September 2000. Disposal Area Monitoring System Contribution 131, US Army Corps of Engineers, New England District, Waltham; MA

Smith EP, Orvos DR, Cairns J Jr (1993) Impact assessment using the before-after-control-impact (BACI) model: concerns and comments. Can J Fish Aquat Sci 50:627-637

Smith SD, Rule MJ (2001) The effects of dredge-spoil dumping on a shallow water soft-sediment community in the Solitary Islands Marine Park, NSW, Australia. Mar Pollut Bull 42(11):1040-1048

Stehlik LL (1993) Diets of the brachyuran crabs Cancer irroratus, C. borealis, and Ovalipes ocellatus in the New York Bight. J Crustac Biol 13(4):723-735

Steneck RS, Wilson CJ (2001) Large-scale and long-term, spatial and temporal patterns in demography and landings of the American lobster, Homarus americanus, in Maine. Fish Bull 52:1303-1320

Stewart-Oaten A (1993) Evidence and statistical summaries in environmental assessment. Trends Ecol Evol 8:156-158

Underwood AJ (1991) Beyond BACI: experimental designs for detecting human environmental impacts on temporal variation in natural populations. Aust J Mar Freshw Res 42: 569-587

Editorial responsibility: Kenneth Heck (Contributing Editor), Dauphin Island, Alabama, USA
Underwood AJ (1994) On beyond BACI: sampling designs that might reliably detect environmental disturbances. Ecol Appl 4(1):3-15

USACE (US Army Corps of Engineers) (1992) Dredged material management program (brochure). NEDEP-360-1-21, New England District, Waltham

Van Dolah RF (1984) Effects of dredging and open-water disposal on benthic macroinvertenrates in a South Carolina estuary. Estuaries 7(1):28-37

Vitousek PM, Mooney HA, Lubchenco J, Melillo JM (1997) Human domination of Earth's ecosystems. Science 277:494-499

Wahle RA, Incze LS (1997) Pre- and post-settlement processes in the recruitment of the American lobster. J Exp Mar Biol Ecol 217:179-207

Wahle RA, Dunnington M, O'Donnell K, Bell M (2004) Impact of dredged sediment disposal on lobster and crab abundance and movements at the Rockland disposal site, Penobscot Bay, Maine. Disposal Area Monitoring System Contribution 154, US Army Corps of Engineers, New England District, Waltham, MA. DACW33-03-D-007 TO5 09000-351-260. Available at www.nae.usace.army.mil/ damos/pdf/154.pdf

Watling L, Norse EA (1998) Disturbance of the seabed by mobile fishing gear: a comparison to forest clearcutting. Conserv Biol 12(6):1180-1197

Watson WH III, Vetrovs A, Howell WH (1999) Lobster movement in an estuary. Mar Biol 134:65-75

Wilber DH, Clarke DG (1998) Estimate secondary production and benthic consumption in monitoring studies: a case study of the impacts of dredged material disposal in Galveston Bay, Texas. Estuaries 21(2):230-245

Ziegler PE, Haddon M, Frusher SD, Johnson CR (2004) Modeling seasonal catchability of the southern rock lobster Jasus edwardsii by water temperature, molting, and mating. Mar Biol 145:179-190

Submitted: May 26, 2005; Accepted: April 2, 2007

Proofs received from author(s): October 3, 2007 